\title{
The Role of Particle Size on Bio-Fouling Properties of Oil-impregnated Nano-porous Silica Coatings
}

\author{
*1 UBUO, EE; ${ }^{1}$ UDO, GJ; ${ }^{2}$ KOFFI, US; ${ }^{3}$ ALSWAFY, OB \\ ${ }^{* 1}$ Department of Chemistry, ${ }^{2}$ Department of Marine Biology, Akwa Ibom State University, Nigeria \\ ${ }^{3}$ Department of Chemistry, University of Hull, UK \\ *Corresponding Author Email: eubuo@yahoo.co.uk
}

\begin{abstract}
The growth of algae, barnacles, moulds and other organisms on ship hulls, concretes, painted or coated surfaces, especially in the tropics, could be harmful and aesthetically unattractive. Control of such growths usually includes the use of coatings that may contain chemicals that can destroy these organisms, and in some cases, other lives. However, manipulation of the topography of material surfaces in the so called Slippery Liquid Infused Porous Surfaces (SLIPS) seems to be excellent safety approach of tackling bio-fouling problems. In this work, we have fabricated hydrophobic silica coatings of different particle sizes, ranging from $10 \mathrm{~nm}$ to $700 \mathrm{~nm}$; the coatings have been impregnated with non-volatile oil (squalane) to obtain artificial rims of Nepenthes Pitcher plant. Wettability and anti-biofouling tests carried out on the fabricated coatings using water drops and algal cell media have shown that surfaces coated with the smallest nano-sized particles $(10 \mathrm{~nm})$ possess better stability and anti-biofouling characteristics toward algae adhesion.
\end{abstract}

\section{DOI: https://dx.doi.org/10.4314/jasem.v23i6.24}

Copyright: Copyright (C) 2019 Ubuo et al. This is an open access article distributed under the Creative Commons Attribution License (CCL), which permits unrestricted use, distribution, and reproduction in any medium, provided the original work is properly cited.

Dates: Received: 05 April 2019; Revised: 11 May 2019; Accepted 21 June 2019

Keywords: Nano-particles, Porous coating, oil-impregnation, bio-fouling, wettability.

Generally, fouling refers to undesired deposition or accumulation of material on surfaces. Such materials may stem from scaling or precipitation of mineral materials, accumulation of particles, organic matters build up, or accumulation of living organisms. The latter is termed biofouling (Flemming, 2002). These organisms can colonise solid surfaces within a short period of exposure to medium that is infested by the organisms. If the organism can successively settle on the surface, they secrete sticky extracellular polymeric substance (EPS) onto the surface and become properly attached (Cortés et al., 2011). The attached cells can then divide rapidly to form colonies that eventually coalesce to form a biofilm, which may grow in thickness up to $500 \mu \mathrm{m}$ (Callow \& Callow, 2002; Heng et al., 2008). Practical consequences of biofouling are quite enormous. The magnitude of problems associated with biofoulings may include: increased drag on submerged part of the ship hull due to the attachment and growth of marine biomass; microbiologically influenced corrosion of metal surfaces, contaminations, as well as stains/difficulty in cleaning. (Darbord, 2004; Kawai, 2002; Kumar \& Anand, 1998; Videla, 2002). In addition to tremendous side effects associated with chemical controls of biofouling, biofilms are known to exhibit effective resistance toward all forms of chemicals intended to kill or control their growth, including antibiotics, biocides and disinfectants (Bixler \& Bhushan, 2012;
Gattlen, et al., 2010). This is because biofilms can exist in various extreme conditions including $\mathrm{pH}$ range between $0.5-14$, temperature from -5 to $120^{\circ} \mathrm{C}$, etc. and are reported as the most successive form of life (Schulte et al., 2004). Surface coating is one of the techniques employed to protect various interfaces from negative environmental consequences. Such coatings often exhibit desirable physical and chemical properties such as colour, thermal and electrical insulations, hardness/wear resistance, anti-corrosion, chemical inertness and low surface energy (Saha et al., 2015). Besides the chemical nature of coating powders, the use of certain range (size) of particles can impart distinctive topographies (roughness) on material and provide perceptions into the fundamental behaviours of the coated material. For instance, applications of micro/nano-sized materials in the fabrications of artificial lotus surfaces (self-cleaning materials) are well known. (Cha et al., 2010; Kim et al., 2011; Song, et al., 2015). Further modifications of such materials by appropriate oil-impregnations have been used to produce the so called Slippery LiquidInfused Porous Surfaces (SLIPS) (Qiu et al., 2014; Rungraeng, et al., 2015; Wang et al., 2015; Yang et al., 2015). Considering the wide range of powder particles employed in coatings industries, investigations to determine the range of their applications become very pertinent. This paper investigates the influence of particle size on wetting

*Corresponding Author Email: eubuo@yahoo.co.uk 
and anti-biofouling properties of silica coatings. Here, hydrophobic silica powders of different particle sizes have been used for the preparation of porous silica substrates followed by the impregnations of porous coating with non-volatile oil (squalane). Finally, wettability and anti-fouling investigations of algae on the coatings have been carried out by measuring contact angles water drops on the surfaces and by exposing the coatings to algal media, respectively.

\section{MATERIALS AND METHODS}

Materials: Aerosil R202 hydrophobic fumed silica was obtained from Evonik Industry and supplied by Lawrence Industry, UK. According to the manufacturer, Aerosil the R202 was produced by subjecting hydrophilic fumed silica to hydrophobisation with polydimethylsiloxane $\left[\begin{array}{ll}1, & 2\end{array}\right]$. No further hydrophobisation of the sample was carried out. Other silica powders $(200-700 \mathrm{~nm})$ - hydrophilic monodisperse silica particles were obtained from Fiber Optic Center Inc. The particles were cleaned ultrasonically by dispersing $5 \mathrm{~g}$ of the particles in $25 \mathrm{ml}$ of ethanol and then agitated for 10 minutes using Grant Ultrasonic bath (MXB6). The samples were then centrifuged for 15 minutes and repeated trice with the replacement of the supernatant using benchtop centrifuge (Sorvall Thermo Scientific). The final settled silica was dried overnight in a vacuum oven at room temperature and then hydrophobised under a constant agitation in 0.1M DCDMS in anhydrous toluene for $1 \mathrm{~h}$ using an air-tight box. Dichlorodimethylsilosane (DCDMS) used as hydrophobisation agent and squalane, the impregnating oil, were obtained from Sigma Aldrich; ethanol and toluene were obtained from Fisher Scientific.

\section{Methods}

Preparation of the dispersion and fabrication of the silica coated slides: Fumed silica dispersions were prepared by adding dry hydrophobic fumed silica in absolute ethanol to form $20 \mathrm{wt} . \%$ (and $5 \mathrm{wt} . \%$ for fumed silica). The mixture was ultrasonically dispersed for 10 min using Branson digital Sonifier (model 450) set at $50 \%$ of the maximum power. About $500 \mu \mathrm{l}$ of the prepared suspension was deposited on 25 by 25 square millimetre microscope slide placed on the sample table of the spin coater (model P6700). The dispersion was uniformly spread and coated onto the each slide at a maximum spin rate of $1500 \mathrm{rpm}$ for $40 \mathrm{~s}$. The resulted porous coated slides were dried in an oven at $100{ }^{\circ} \mathrm{C}$ for $1 \mathrm{~h}$ and on cooling, $100 \mu \mathrm{L}$ of squalane was deposited on as prepared porous coated slides and placed on the sample table of a spin coater and spun at $1500 \mathrm{rpm}$ to obtain oil-impregnated coated slide. The impregnated surface was transferred to a vacuum desiccator for an hour to ensure a complete evacuation of air and infiltration of the oil.
Measuring contact angles of water drop on the prepared surfaces: Contact angles of water drops on the fabricated coatings in air were investigated by measuring advancing and receding contact angles of $10 \mu \mathrm{L}$ of sessile water drops on the surfaces using drop shape analysis instrument, (DSA 10, Kruss). Water drops was dispensed and withdrawn from the surfaces of the sample placed on the sample stage of the instrument using a syringe pump (New Era) fitted with PTFE tubing and needle.

Adhesion of algae cells on the fabricated surfaces: The algae culture media was prepared as reported by Al-Awady et al., (2016). The stock solution (culture media) of the cell sample was diluted to obtain an average cell concentration within the range of $(5 \pm 1) \times 10^{6}$ cell $/ \mathrm{ml}$ using cellometer (Nexcelom Bioscience). The prepared surfaces were placed in glass Petri-dishes and $40 \mathrm{ml}$ of the algae media added to fully cover the slides. The slides were kept submerged for 6 hours and then removed and vertically dipped into a beaker of milli-Q water to remove non-adhering algal media from the surface. Cover slip was placed on the surface of each slide and placed inder microscope for further investigations. At least five (5) different spots on each slide were focused and the number of adhered algae cells counted using optical microscope.

\section{RESULTS AND DISCUSSION}

Morphology of the silica coatings: Figure 1 provides SEM images of dry silica coatings of different particle sizes. Interesting trend gathered from the SEM image is the gradual aggregation of the particles with decrease in the size. Larger particles (bottom of the image) are distinctive as a separate entity in full diameter. As the particle size reduces, aggregation of particles sets in and gradually builds up; this increases upward to a reasonable state at 300 and $200 \mathrm{~nm}$ particles. In the case of fumed silica, the degree of aggregations so high that it becomes difficult to identify primary particles with diameter $10 \mathrm{~nm}$. Also, as the particle size gets smaller, the aggregation of particles changes the surface roughness of the coatings from being dependent on the size of the particles to a combination of the primary particles and aggregated particles, leading to hierarchical or multiscale of roughness.

Wettability of the dry coated surfaces: The advancing and receding contact angles of water drops of the different coatings in air is shown in Figure 2. 


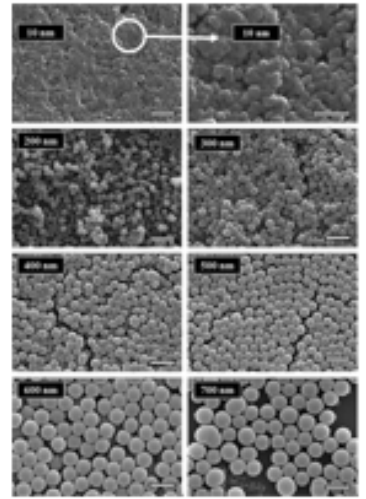

Fig 1: Scanning electron microscope images of porous coatings made of different sizes of silica particles. The top images show 10 $\mathrm{nm}$ particles coating at different magnification. All other scale bars represent $100 \mathrm{~nm}$ except the top right image which represents 500 $\mathrm{nm})$.

From the plots, it is seen that $10 \mathrm{~nm}$ coatings exhibit superhydrophobic nature with an average contact angle of $165 \pm 5$ and negligible hysteresis. From this point, the contact angle of water drops on the coatings decreases with increasing particle size up to $700 \mathrm{~nm}$ coatings (with remarkable contact angle hysteresis). 10 $\mathrm{nm}$ coatings have the tendency to provide robust wetting stability certainly due to fine capillary air pockets on the structures generated by aggregations and formation of multiscale of roughness observed in Fig. 1 and reported earlier (Bormashenko et al., 2007; Latthe, et al., 2012; Sheng, et al., 2007). Larger particles provide larger pores, less roughness, less capillary air pressure, hence, the observed decrease in contact angle and higher hysteresis.

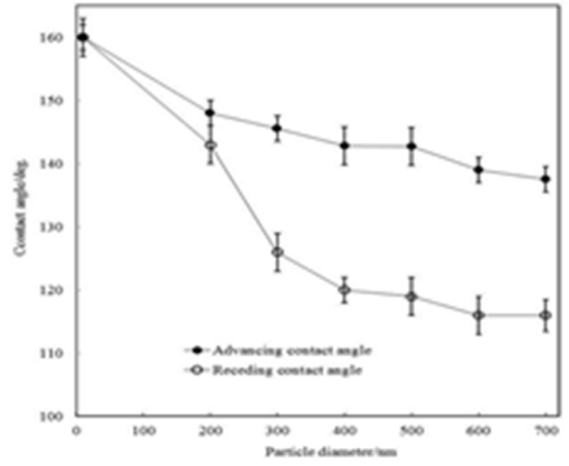

Fig 2 Variation of advancing and receding contact angles of water drops on silica coatings made of silica particles with different diameters in air.
Algae cells adhesion on the coatings: Algae cell adhesion results on the dry and oil-impregnated coatings are presented in Figures 3 and 4. Figure 3 is the selected optical microscope images of the dry and impregnated coatings exposed to algae media for 6 hours and Figure 4 is the plot comparing the effect of silica particles on anti-biofouling property of the dry and impregnated fabricated coatings.

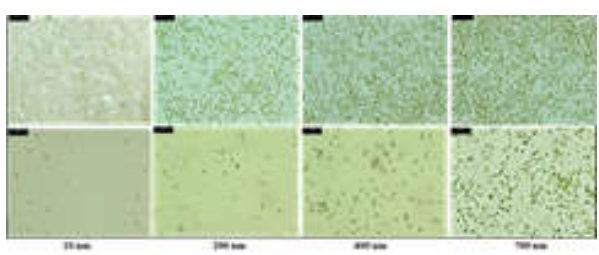

Fig 3. Optical microscope images comparing adhesion of algae on silica coatings with different particle sizes: dry, (or nonimpregnated) coatings (top) and oil-impregnated coatings (bottom) Scale bar represent $50 \mu \mathrm{m}$

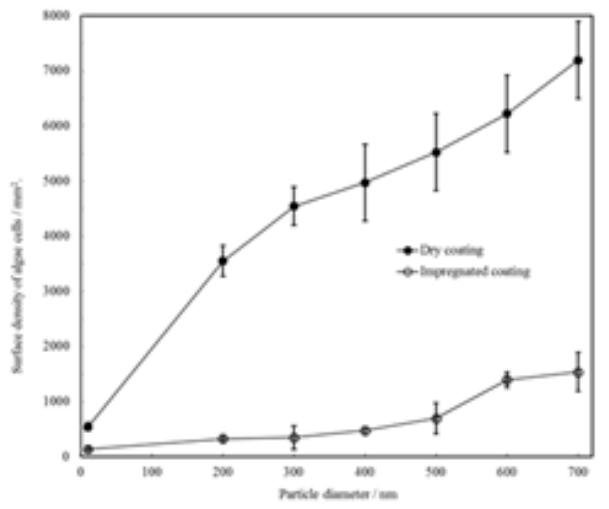

Fig 4. Plots showing effect of the size of silica particles on antibiofouling property of the dry and impregnated coatings.

From the above findings, it is quite clear that coatings with smaller particle sizes exhibit higher antibiofouling property whereas coatings with bigger particles show less anti-biofouling characteristics. We believe that the highly textured coatings with smaller particle sizes only allow algae cells to rest on the tips, or very small portion of the solid and could easily be washed off during turbulent flow or rinsing with water. On the contrary, less structured coatings provide wider pores or furrows between particles, and such roughness could even provide hiding places for the cells thereby allowing them to established adequate contact with the material surface which resulted to high degree of bio-fouling (Figure 5). Impregnated coatings are also observed to exhibit better anti-fouling behaviours compared to the dry coatings. This can be attributed to the role of the oil to seal the roughness on the coatings that usually promote adhesion. Squalane 
that replaces the material interface is slimmer and generally reduces grip and therefore poor adhesion. However, the stability of the oil on silica coatings with larger particles (less textured) is definitely not as good as the highly textured fumed silica coatings with finer capillaries.

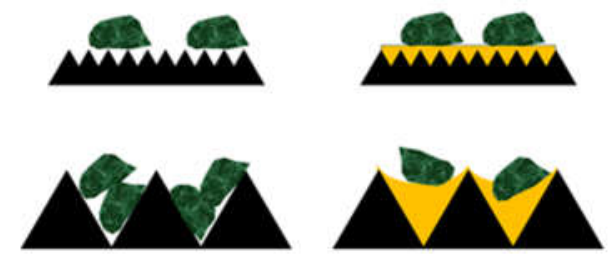

Fig 5. Illustration depicting both the dry (LHS) and oil-impregnated (RHS) of smaller (top) and bigger (bottom) particle-sized coatings. The smaller particle sized coating only allows the cells to rest on the tips of the textured coating and also provides a stable impregnated coated surface. The bigger particle-sized coatings possess large grooves that can accommodate cells and enhance stronger adhesion against turbulent flow and its impregnated coatings provides less stable oil surface.

Conclusion: Silica coatings with finer particle sizes showed better stability against wettability and biofouling compared to coatings with larger silica particles. Considering environmental concerns associated with toxic antifouling coatings, selection of appropriate nano-sized powders in coating formulation appears to be an alternative and environmentally friendly method of bio-fouling control.

Acknowledgments: This research was supported by grant from the Tertiary Education Trust Fund (TetFund) of Nigeria. The authors are grateful to Dr Tommy Horozov and Prof Vesselin Paunov for useful discussions.

\section{REFERENCES}

Al-Awady, M. J., Greenway, G. M., Paunov, V. N. (2015). Nanotoxicity of polyelectrolytefunctionalized titania nanoparticles towards microalgae and yeast: role of the particle concentration, size and surface charge. Rsc Advances, 5(46), 37044-37059

Bixler, G. D., Bhushan, B. (2012). Biofouling: lessons from nature. [Review]. Philos Trans A Math Phys Eng Sci, 370(1967), 2381-2417

Bormashenko, E., Bormashenko, Y., Stein, T., Whyman, G., Bormashenko, E. (2007). Why do pigeon feathers repel water? Hydrophobicity of pennae, Cassie-Baxter wetting hypothesis and
Cassie-Wenzel capillarity-induced wetting transition. J Colloid Interface Sci, 311(1), 212216

Callow, M. E., Callow, J. A. (2002). Marine biofouling: a sticky problem. Biologist, 49(1), 1-5

Cha, T. G., Yi, J. W., Moon, M. W., Lee, K. R., \& Kim, H. Y. (2010). Nanoscale Patterning of Microtextured Surfaces to Control Superhydrophobic Robustness. Langmuir, 26(11), 8319-8326.

Cortés, M. E., Consuegra, J., Sinisterra, R., MendezVilas, A. (2011). Biofilm formation, control and novel strategies for eradication. Science Against Microbial Pathogens: Communicating Current Research and Technological Advances, 2, 896905.

Darbord, J. C. (2004). Importance of cleaning for reprocessing endoscopes and thermolabile sterile medical devices: French use and regulations. $J$ Hosp Infect, 56 Suppl 2, S40-43

Flemming, H. C. (2002). Biofouling in water systems - cases, causes and countermeasures. Applied Microbiology and Biotechnology, 59(6), 629-640

Gattlen, J., Amberg, C., Zinn, M., Mauclaire, L. (2010). Biofilms isolated from washing machines from three continents and their tolerance to a standard detergent. [Research Support, Non-U.S. Gov't]. Biofouling, 26(8), 873-882

Genzer, J., Efimenko, K. (2006). Recent developments in superhydrophobic surfaces and their relevance to marine fouling: a review. [Research Support, U.S. Gov't, Non-P.H.S. Review]. Biofouling, 22(5-6), 339-360

Heng, L., Yanling, Y. L., Weijia, G. J., Xing, L., Li, G. B. (2008). Effect of pretreatment by permanganate/chlorine on algae fouling control for ultrafiltration (UF) membrane system. Desalination, 222(1-3), 74-80

Kawai, F. (2002). Microbial degradation of polyethers. Applied Microbiology and Biotechnology, 58(1), 30-38.

Kim, D. H., Kim, Y., Kim, B. M., Ko, J. S., Cho, C. R., Kim, J. M. (2011). Uniform superhydrophobic surfaces using micro/nano complex structures formed spontaneously by a simple and costeffective nonlithographic process based on anodic 
aluminum oxide technology. Journal of Micromechanics and Microengineering, 21(4)

Kumar, C. G., Anand, S. K. (1998). Significance of microbial biofilms in food industry: a review. International Journal of Food Microbiology, 42(1-2), 9-27

Latthe, S. S., Gurav, A. B., Maruti, C. S., Vhatkar, R. S. (2012). Recent Progress in Preparation of Superhydrophobic Surfaces: A Review. J Surf Eng Mater Adv Technol, 02(02), 76-94

Qiu, R., Zhang, Q., Wang, P., Jiang, L. N., Hou, J., Guo, W. M., Zhang, H. X. (2014). Fabrication of slippery liquid-infused porous surface based on carbon fiber with enhanced corrosion inhibition property. Colloids and Surfaces aPhysicochemical and Engineering Aspects, 453, 132-141

Rungraeng, N., Yoon, S. H., Li, Y., Jun, S. (2015). Development of a Self-Slippery Liquid-Infused Porous Surface (Slips) Coating Using Carbon Nanotube Composite for Repelling Food Debris and Microbial Biofilms. Transactions of the Asabe, 58(3), 861-867

Saha, B., Toh, W. Q., Liu, E., Tor, S. B., Hardt, D. E., Lee, J. (2015). A review on the importance of surface coating of micro/nano-mold in micro/nano-molding processes. Journal of Micromechanics and Microengineering, 26(1)

Schulte, S., Wingender, J., Flemming, H.-C. (2004). Efficacy of biocides against biofilms Directory of Microbicides for the Protection of Materials (pp. 93-120): Springer
Sheng, Y. J., Jiang, S., Tsao, H. K. (2007). Effects of geometrical characteristics of surface roughness on droplet wetting. J Chem Phys, 127(23), 234704.

Song, K. M., Ahn, S. H., Cho, Y. S. (2015). Fabrication of a hierarchical aluminum oxide surface with micro/nanostructures via a single process and its application as a superhydrophobic surface: Simple sintering method with an aluminum microsized powder. Surface \& Coatings Technology, 282, 68-77

Videla, H. A. (2002). Prevention and control of biocorrosion. International Biodeterioration \& Biodegradation, 49(4), 259-270.

Wang, P., Zhang, D., Lu, Z. (2015). Slippery liquidinfused porous surface bio-inspired by pitcher plant for marine anti-biofouling application. Colloids and Surfaces B-Biointerfaces, 136, 240247.

Wong, T. S., Kang, S. H., Tang, S. K., Smythe, E. J., Hatton, B. D., Grinthal, A., Aizenberg, J. (2011). Bioinspired self-repairing slippery surfaces with pressure-stable omniphobicity. Nature, 477(7365), 443-447.

Yang, S. S., Qiu, R., Song, H. Q., Wang, P., Shi, Z. Q., Wang, Y. F. (2015). Slippery liquid-infused porous surface based on perfluorinated lubricant/iron tetradecanoate: Preparation and corrosion protection application. Applied Surface Science, 328, 491-500 